Rechtsmedizin 2018 - 28:537-538

https://doi.org/10.1007/s00194-018-0280-4

Published online: 17 October 2018

(c) Springer Medizin Verlag $\mathrm{GmbH}$, ein Teil von Springer Nature 2018

CrossMark

\title{
A. Siems
}

Institute of Legal Medicine, University Hospital, Goethe-University, Frankfurt/Main, Germany

\section{Erratum to: Homicide-suicide. Postmortem study from the Institute of Legal Medicine in Frankfurt/Main from 1994 to 2014}

\section{Erratum to:}

Rechtsmedizin 2017. 27:175-184

https://doi.org/10.1007/s00194-017-

0161-2

In the original publication under the heading "Results", a number of 11 double suicide cases was given. The correct number is 18. In addition to that the correct number of total autopsy cases is 78 . The correct paragraph is printed here:

\section{Results}

The analysis of the forensic database of the Institute of Legal Medicine in Frankfurt/Main led to 78 autopsy cases. We excluded 18 cases because they were defined as a double suicide, 2 cases were excluded because of indefinability of homicide-suicide or double suicide and 58 cases of homicide-suicide were finally included and analyzed.

We apologize for the mistake.

\section{Corresponding address}

\section{A. Siems}

Institute of Legal Medicine, University Hospital, Goethe-University

Kennedyallee 104, 60596 Frankfurt/Main Germany

s1690708@stud.uni-frankfurt.de 
Hier steht eine Anzeige.

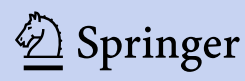

